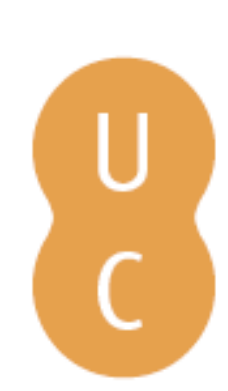

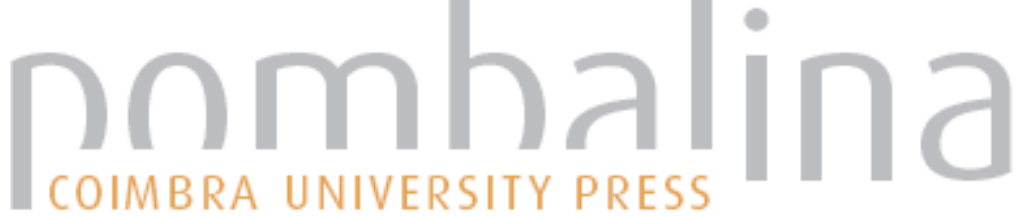

\section{Os usos sociais dos rios}

\author{
Autor(es): Peixoto, Paulo
}

Publicado por: Imprensa da Universidade de Coimbra

URL

persistente: URI:http://hdl.handle.net/10316.2/39318

DOI: $\quad$ DOI:http://dx.doi.org/10.14195/978-989-26-1025-2_3

Accessed : $\quad$ 26-Apr-2023 16:17:50

A navegação consulta e descarregamento dos títulos inseridos nas Bibliotecas Digitais UC Digitalis, UC Pombalina e UC Impactum, pressupõem a aceitação plena e sem reservas dos Termos e Condições de Uso destas Bibliotecas Digitais, disponíveis em https://digitalis.uc.pt/pt-pt/termos.

Conforme exposto nos referidos Termos e Condições de Uso, o descarregamento de títulos de acesso restrito requer uma licença válida de autorização devendo o utilizador aceder ao(s) documento(s) a partir de um endereço de IP da instituição detentora da supramencionada licença.

Ao utilizador é apenas permitido o descarregamento para uso pessoal, pelo que o emprego do(s) título(s) descarregado(s) para outro fim, designadamente comercial, carece de autorização do respetivo autor ou editor da obra.

Na medida em que todas as obras da UC Digitalis se encontram protegidas pelo Código do Direito de Autor e Direitos Conexos e demais legislação aplicável, toda a cópia, parcial ou total, deste documento, nos casos em que é legalmente admitida, deverá conter ou fazer-se acompanhar por este aviso.

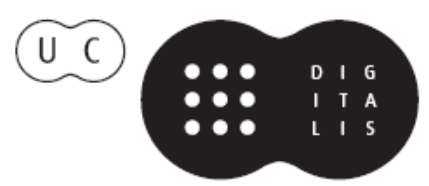




\section{OS USOS SOCIAIS DOS RIOS}

PAULO PEIXOTO 


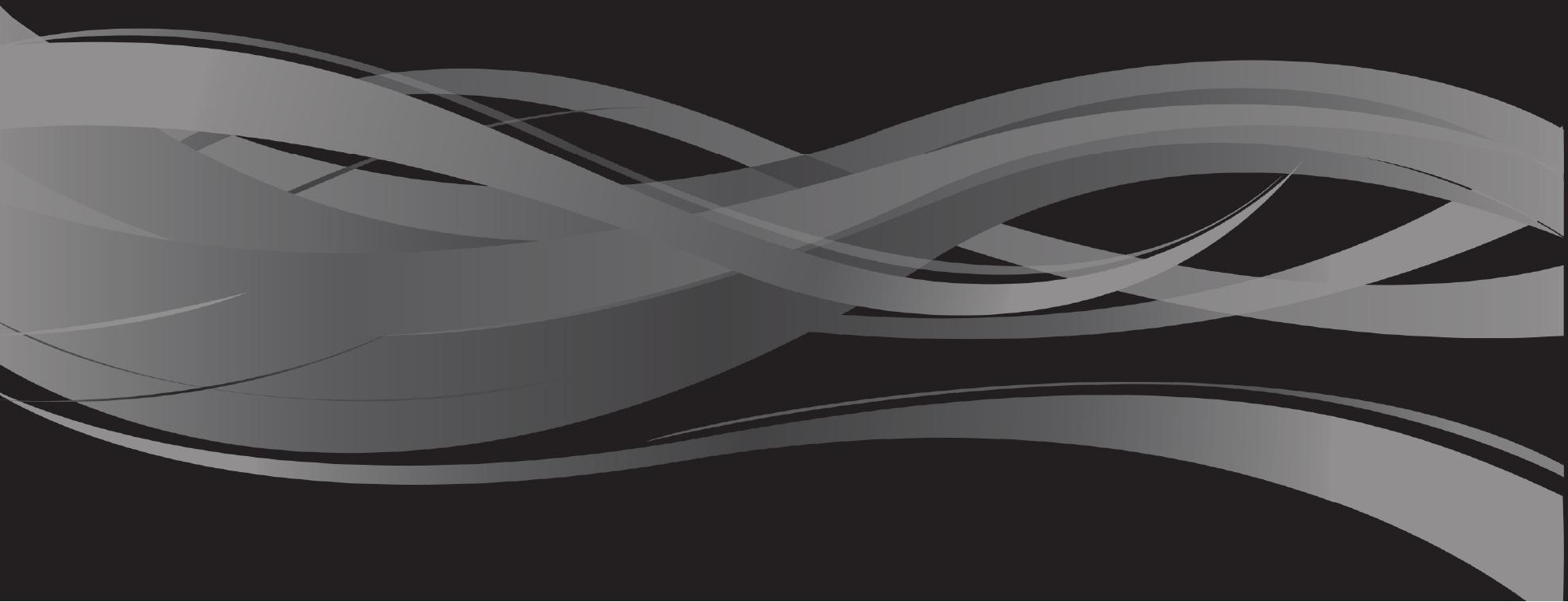




\section{NASCENTE}

E se os rios nascessem no mar? Poder-se-ia contar a história dos rios ao contrário, enfatizando o seu caráter natural ou selvagem em vez de os revelarmos enquanto produtos da intervenção humana? A questão sociologicamente relevante é a de saber até que ponto se pode reverter a situação catastrófica a que muitos rios chegaram em virtude dos usos sociais que foram preenchendo ao longo da sua história. Para muitos autores, que lamentam a excessiva intervenção humana nos rios, e que se referem expressivamente à "vida e morte dos rios", valeria a pena inverter a história dos rios de modo a evitar que tivessem chegado ao estado atual. Mas, para esses autores, parece não ser possível uma reversão aceitável. Outros autores exaltam a transformação dos rios ao longo dos séculos, enfatizando que essa transformação permite dar conta que a relação humanidade/natureza e tecnologia/ambiente são um continuum de um mesmo assinalável processo civilizacional. A verdade é que, ao longo dos séculos que nos antecederam, os rios sofreram transformações profundas nos seus usos sociais e económicos. Christof Mauch e Thomas Zeller, para demonstrarem que a ascensão das civilizações sempre esteve ligada ao modo bem sucedido como geriram a água, citam Lewis Mumford para lembrar que "todas as grandes culturas históricas ... fluíram através do movimento dos homens, das instituições, das invenções e das mercadorias ao longo das autoestradas naturais de um grande rio" (Mauch e Zeller, 2008: 1)

\section{Os rios - um fator civilizacional}

As grandes cidades das civilizações antigas situavam-se nas margens dos rios. Entre outras, poderiamos destacar: Babilónia e Ur (no rio Eufrates), Ninive (no rio Tigre), Mohenjo Daro (no rio Indo), Tebas e Mênfis (no rio Nilo). O mesmo se pode dizer para as comunidades pré-colombianas na América central, ou para as bacias hidrográficas da Indía e da China. O curso do rio Amarelo (Huang He) e o curso do rio Azul (Yangtzé) concentram, desde há séculos, grande parte da história, da cultura e da economia chinesas. O chamado Crescente Fértil, delimitado pelos rios Jordão, Eufrates, Tigre e Nilo, aglomera as cidades mais antigas de que há memória, assumindo o estatuto de 'berço da civilização humana' (Schneider, s. d.). Foi aí que, com a invenção da agricultura, as dinâmicas de sedentarização se iniciaram e que o processo civilizacional ganhou um novo rumo.

A invenção da economia agrícola, que simboliza a existência da propriedade privada, ora é vista como tendo sido uma benção, ora é vista como a tragédia da civilização humana. Independentemente das vantagens e das desvantagens da substituição do nomadismo baseado na caça e na pastorícia (questão que hoje está filosoficamente ultrapassada), é inegável que a agricultura foi o principal fator de sedentarização e que os rios foram determinantes no estabelecimento e na evolução da economia agrícola. Sendo evidente que a sedentarização, no modo e na velocidade com que evoluiu, trouxe novos desafios e novos riscos à humanidade, constituindo um marco civilizacional irreversível. A invenção da agricultura no Crescente Fértil não tem só a ver com técnicas de cultivar 
a terra, nem corresponde apenas ao salto civilizacional que liberta a humanidade dos ritmos e das disponibilidades da natureza. Corresponde também ao desenvolvimento das formas de organização social que marcam o nosso processo civilizacional; designadamente a divisão social do trabalho, a formatação das trocas comerciais e o progresso científico e técnico que alastra a todas as atividades humanas e áreas do social.

Muitas das dinâmicas sociais que aparecem funcional e simbolicamente associadas aos rios têm a sua origem na invenção da agricultura e na evolução do processo de sedentarização. Na sua dimensão civilizacional, os rios são um fator determinante do povoamento humano. Primeiro na busca das terras mais férteis. Depois, com o crescimento demográfico, na expansão territorial das comunidades. Ou ainda na escolha da localização mais adequada para desenvolver o comércio que se estabeleu entre locais dispersos, mas que os rios permitiam ligar enquanto veículos primordiais de circulação. Marcam indelevelmente os sistemas construtivos locais tradicionais, quer pelos materiais que são extraídos dos seus leitos e margens, quer pelos materiais que permitiam transportar. Mas estão também presentes na emergência de guerras e de conflitos inerentes à defesa da propriedade e à conquista das melhores localizações estratégicas. Como ainda na evolução técnica e tecnológica. Não é por acaso que muitas das atuais fronteiras são delimitadas por rios. Não é por acaso que a maior parte das capitais nacionais são atravessadas por rios. Como não é por acaso que os rios, hoje como no passado, sempre tenham sido alvo de grandes e experimentais obras de engenharia (pontes, barragens, diques, canais, mudanças artificiais de leito, etc) que traduziram a capacidade de inovação humana. Os rios são documentos que permitem ler a história dos lugares, retratar os episódios marcantes e dar conta das dinâmicas sociais presentes em cada momento da nossa existência.

Os rios correm para outros rios ou correm para mar. Metaforicamente, a humanidade corre, também ela, para o mar. Mas há algo nestas duas 'corridas' que é mais significativo que a coincidência da metáfora. A concentração crescente da população mundial junto aos cursos de água e, sobretudo, na orla costeira do planeta, revela bem a importância civilizacional dos rios. Dos aglomerados populacionais que se estabeleceram com a expansão da agricultura e o crescimento demográfico que ela motivou; passando pelo facto de os rios terem funcionando durante séculos enquanto 'estradas naturais', que fomentaram novas dinâmicas económicas (comerciais e industriais) e, com elas, o crescimento urbano; não esquecendo que os vales cavados pelos rios facilitaram as infraestruturas modernas (do caminho de ferro às autoestradas), mesmo onde o relevo era adverso; e, não menos importante, que os rios estruturaram as hierarquias urbanas, ou pelas riquezas que geraram, ou por terem mudado naturalmente de curso e de, com isso, terem refeito a ordem de importância das cidades; os rios contribuiram significativamente para formatar a civilização em que vivemos.

Vivemos em civilizações urbanas. Mais de metade da população mundial vive em cidades e as grandes metrópoles não param de aumentar em número e em dimensão. A relação entre rios e cidades é uma marca da nossa civilização. A relação entre a cidade e o rio que a atravessa pode ter-se alterado ao longo da história. Mas rios e cidades são indissociáveis. Uma das características mais marcantes da transição de século que vivemos é, sem dúvida, a conversão das paisagens fluviais em paisagens urbanas. 


\section{Rio abaixo, rio acima - narrativas sobre os rios}

Tendo uma inegável relevância civilizacional, não é de estranhar que os rios se tornem objeto de abordagens transversais e que interessem a todas as áreas do conhecimento científico. Da física à música, da engenharia ao light design, da economia à política, da religião a todas as formas de arte e expressões culturais, as narrativas sobre os rios são muitas e diversas.

Desde que a sedentarização se concretizou nas suas margens que os rios geram experiências e sentimentos dissonantes. O mesmo rio que traz a fertilidade e o alimento na sua corrente pode trazer animais que matam, doenças ou águas poluídas. O mesmo rio que corre tranquilo no seu leito extravasa dele com violência numa fúria destruidora. O mesmo rio onde uns se divertem, nadando e passeando, é o mesmo rio onde outros sofrem as agruras do trabalho e por vezes da escravidão. O mesmo rio que é um obstáculo à mobilidade, constituindo-se como fronteira, é via de circulação.

As narrativas sobre os rios estão presentes nos livros sagrados assim como na literatura contemporânea, sendo importantes para darmos conta dos usos sociais e das especificidades dos rios. Mas também para dar conta que muitas das narrativas passadas mantêm uma atualidade impressionante e que várias dessas narrativas, fazendo parte de um passado remoto num contexto, são o presente de muitos outros contextos. A Bíblia, por exemplo, refere-se a todos os rios do Crescente Fértil relevando aquelas que eram as suas principais funções. Se o rio Jordão (numa característica que guardou mesmo nos tempos pósbiblicos) se apresenta como um rio que não é importante pela sua navegabilidade, mas enquanto barreira natural e fronteira política, o Nilo fica conhecido pela violência das suas cheias e pelas pragas que o seu curso fazia chegar. Juntamente com o Tigre e o Eufrates partilha as narrativas da abundância e da fome, mostrando bem a relação dos rios com a economia e os dramas recorrentes da humanidade, assim como a manutenção da importância que os rios já tinham nos tempos biblicos e a relevância dessa narrativa perante a realidade de, ainda hoje, 95\% da população do Egito depender da produtividade de $5 \%$ do solo nacional, precisamente localizado no leito de cheia do rio Nilo (Kelm, 1991). O Tigre e o Eufrates, que aparecem na Bíblia como dois dos quatro rios dos Jardins do Éden, e como braços do rio principal que regava o Éden, passam grande parte da sua história a mudar misteriosamente o seu curso e a formar novos braços, tal como ainda hoje $90 \%$ do seu caudal não chega ao Golfo Pérsico, perdendo-se entre a irrigação e a evaporação. A sua história e a dos dois restantes rios do Éden participa na narrativa dos rios desaparecidos, uma realidade que não é assim tão incomum se considerarmos os rios que, por razões naturais ou artificiais, mudaram de curso ou os rios que se tornaram subterrâneos em virtude dos processos de ocupação do solo ou de acidentes geológicos. Narrativas que tanto nos trazem à memória as cidades e aldeias que desaparecem ou perdem importância quando os rios mudam de curso, quanto aquelas que conhecem igual destino quando as barragens engrossam os caudais.

O vasto campo da cultura, da "Noite estrelada sobre o Rio Ródano" (de Vincent van Gogh) ao "Danúbio Azul" (de Johann Strauss), passando por "Memórias de um turista" (de Stendhal), entre tantos outros, está cheio de exemplos que enfatizam a relação entre os rios e o imaginário social. Nas artes e na vida, o rio faz flutuar as memórias, cria valores partilhados por comunidades diversas e faz emergir 
normas e instituições. O imaginário social que os rios sustentam junto das comunidades que atravessam cria narrativas que definem modos de convivência e de representação da sua vida coletiva. Vários autores registaram afinidades entre os rios e as comunidades com eles relacionadas: o Reno e as suas gentes são românticos; o Tamisa é imperial; o Ródano é selvagem (Mauch e Zeller, 2008). Nessa dimensão simbólica que o imaginário social transporta, os rios fascinam e criam ilusões que podem ter efeitos reais e que podem abrir portas à mudança e à inovação. As narrativas literárias, que retêm muitos dos imaginários sociais relativos aos rios, mostram que o imaginário de "subir o rio" está muito presente no novo mundo, ligado ao facto de os colonos desembarcarem nos portos e transportarem consigo o desejo de aventura e de descoberta, assim como a ansiedade de levar a civilização até às origens mais selvagens. Em contraste, as narrativas do "descer o rio" parecem estar ligadas à aceitação de nos confinarmos ao destino, de aceitar o curso natural das coisas e de caminhar em relação a um fim: o progresso (McMillin, 2011). Acima de tudo, o que a diversidade de narrativas nos mostra é que a relação entre rios e comunidades, entre rios e cidades ou entre rios e civilizações tem de ser sempre contextualizada.

Na relação que os rios mantêm com as cidades, as narrativas que estão na origem de visões partilhadas da realidade e que originam uma espécie de inconsciente coletivo, tornam-se evidentes na forma como os rios contribuem para a formação de um ethos de cidade. Se as cidades são entidades caracterizadas pela diversidade e pela mudança, elas guardam, todavia, um ethos identitário que carrega o peso da sua história e das referências socialmente partilhadas. Se umas se veem e são vistas, sobretudo, como cidades comerciais, industriais, turísticas, entrepostos agroalimentares ou outra coisa qualquer, isso deve-se, com grande frequência, ao modo como os rios criaram referências simbólicas e modos de viver e de representar a vida coletiva dos indivíduos.

\section{Os rios como despojos da civilização}

Quando, em 1850, a Câmara Municipal de Lyon, confrontada com a ausência de uma morgue municipal, decide instalá-la num barco-morgue, na margem direita do Ródano, fê-lo por duas razões essenciais. Por uma questão de centralidade, uma vez que era absolutamente fundamental que a morgue fosse acessível para que os habitantes locais pudessem proceder à identificação dos corpos e para que funcionasse na proximidade dos serviços mortuários. Mas também porque o rio era a melhor via de transporte de cadáveres, sendo, além disso, ele próprio, de acordo com as estatísticas, o maior depósito de cadáveres não identificados (Vettorello e Vignau, s. d.: 124). As razões desta escolha não dizem tudo sobre os rios, mas são reveladoras das funções sociais que eles foram assumindo ao longo da história. Chegados ao século XIX, as funções sociais de centralidade e de transporte são ainda evidentes. Mas é igualmente evidente que os rios se foram convertendo em contentores de detritos orgânicos e inorgânicos de uma civilização crescentemente urbana.

Como referimos, o crescimento da civilização urbana foi ocorrendo, sobretudo, junto aos cursos de água. Esse crescimento caracterizou-se pela emergência de novas cidades e povoados. À entrada 
do século XIX, só Pequim tinha mais de 1 milhão de habitantes, 7 das 10 cidades mais povoadas eram asiáticas e 3 (Londres, Paris e Nápoles) eram europeias. Todas elas ou eram atravessadas por rios ou situavam-se junto ao mar. Um século depois, consumada a Revolução Industrial na Europa, as 10 maiores cidades tinham ultrapassado todas elas a fasquia de 1 milhão de habitantes, sendo Londres a mais povoada, com mais de 6 milhões de pessoas. Mais de metade (6) dessas 10 cidades eram europeias e 4 estavam situadas nos EUA. Num século, a mudança foi radical, quer em termos geográficos, quer em termos demográficos. Só uma coisa se manteve. Todas as 10 maiores cidades do mundo no início do século XX ou eram atravessadas por rios ou se situavam junto ao mar. Chegados ao século XXI, a mudança volta a ser radical, uma vez que há 3 novas cidades sul-americanas entre as 10 mais populosas, uma norte-americana e 6 asiáticas. Destas 10 cidades, onde já não há nenhuma europeia, só Tóquio (que já fazia parte da lista em 1800 e em 1900) e Nova lorque (que em 1900 integrava as 10 mais populosas) se mantêm. Todas as outras são cidades que cresceram no século XX, 3 das quais situadas na Índia. Curiosamente, uma das mais populosas, se não a mais populosa (a cidade do México) não é nem costeira, nem atravessada por um rio, situando-se a mais de 2000 metros de altitude. Mas no seu súbito crescimento, engoliu cerca de 70 rios que a atravessavam e que, entretanto, se tornaram subterrâneos. André Guillerme, ao analisar a história da água na civilização ocidental, sublinha que:

"Textêis, couros, papel e nitratos representam em volume a maior parte dos produtos transformados nas e pelas cidades até ao início do século XVIII. Os seus modos de produção dependem intimamente da humidade e da putrefação, ou sobretudo da quantidade de excrementos produzidos na cidade. A água e o esterco são na economia artesanal riquezas fundamentais que é preciso armazenar e acumular. Neste sentido, os detritos e a água estão para o artesão como o ouro e o dinheiro estão para o Estado no quadro da economia mercantilista." (...) É por isso que desde sempre, as margens dos grandes rios ladeados de grandes florestas foram escolhidas para a construção das grandes cidades (...)" (Guillerme, 1983: 169).

Por estranha e ousada que possa parecer esta explicação de André Guillerme, a verdade é que, chegados ao século XVIII, a civilização urbana, e a sua organização social e económica, vivem profundos problemas de insalubridade. Os rios continuam a ser uma peça-chave do desenvolvimento económico e continuam a estruturar as funções sociais dominantes. Uma das pretensas vantagens do barco-morgue de Lyon era a de conservar os corpos através da sua humidificação, na medida em que permitia uma irrigação contínua dos cadáveres através de um sistema de bombas que traziam a água do rio para cima dos cadáveres de modo a travar a sua putrefação, devolvendo depois a água ao rio. Noutros continentes, da China à América do Sul, onde o desenvolvimento económico e o crescimento demográfico não colocavam uma pressão tão grande sobre as cidades e os rios, a mesma tendência se registava. Era sobretudo uma questão de tempo e de escala. Mas os rios estavam a tornar-se, globalmente, os contentores dos despojos da civilização urbana. No início do século XIX, o caudal do Rio Pelotas - que servia de matadouro para a produção de charque que alimentava os escravos brasileiros, e para escoar os detritos orgânicos das vacas mortas nesse processo - tinha uma inusitada cor vermelha 
e um cheiro não menos estranho. Por tudo isso, André Guillerme sustenta que "A putrefação adere à cidade como a humidade que se cola a este longo período de arrefecimento climático. Uma e outra determinaram a riqueza da cidade; quanto mais uma cidade cheira mal, mais ela é rica. A putrefação é um suporte da urbanização (...)" (Guillerme, 1983: 179).

Confirmando esta ideia que relaciona de forma estreita putrefação e urbanização, durante toda a Idade Média europeia - dada a especificidade das cidades medievais: fechadas sobre si próprias, com ruas estreitas que são uma extensão da casa e das funções domésticas, onde as funções residenciais se misturam ainda com as funções artesanais e produtivas em espaços exíguos -, a água é um elemento presente, circundante e visualizável. ${ }^{2}$ Mas, como bem nota Gabriele Lechner, os rios, nos seus fluxos urbanos, parecem estar irreversivelmente convertidos em coletores de águas usadas e nauseabundas (Lechner, 2006: 7). O espírito das Luzes, no século XVIII, e o movimento higienista, na primeira metade do século XIX, transportam reações filosóficas e práticas a esta situação, até porque a Revolução Industrial e um crescimento demográfico cada vez mais intenso vieram agravar uma situação que se mostrava cada vez mais como insustentável.

Gabriele Lechner (Lechner, 2006) mostra que, em nome da higiene e da salubridade, se assiste progressivamente a um processo de domesticação dos rios e de "desidratação das cidades" e que, no âmbito desse processo, a água vai sendo retirada da vida quotidiana dos cidadãos. A Revolução Industrial, por sua vez, vem consumar a separação entre os rios e as cidades. Mas isso não significa que os rios se tenham libertado das agruras da urbanização e da civilização. Pelo contrário, aos detritos domésticos e artesanais vieram juntar-se os detritos industriais. Nessa medida, a condição de invisibilidade dos rios enfatiza a sua função de reservatório dos despojos da civilização. O lançamento de esgotos domésticos e industriais nos rios das duas maiores cidades europeias da primeira metade do século XVIII (Paris e Londres) originou vários surtos de cólera que mataram milhares de pessoas. Nada de muito diferente do que se passa na Índia dos nossos dias. Por um lado, os rios parecem desaparecer em detrimento dos portos, que passam a concentrar as atividades fluviais mais relevantes. Por outro lado, as fábricas e armazéns tomam conta das margens dos rios, quer porque os rios continuam a ser meios de transporte privilegiados, quer porque os cursos de água são fundamentais para alimentar caldeiras e moinhos, quer ainda porque os rios são a solução mais fácil para fazer desaparecer os despojos industriais. Esta realidade foi sobretudo visível na Inglaterra dos séculos XVIII e XIX, onde muitas cidades conheceram mudanças drásticas e se tornaram irreconhecíveis. A Inglaterra dessa época é vista como um lugar onde os rios são divididos, os canais são repentinamente rasgados e as montanhas minadas. Mas é também um país onde o desenvolvimento das cidades que conheceram um impacto mais forte da Revolução

2 Na obra "Paris au Moyen Âge", Pascal Varejka (Varejka, 1998) dá conta desses usos ancestrais que atravessaram toda a Idade Média, quando afirma que a salubridade das ruas não era a primeira preocupação dos habitantes da cidade, uma vez que atiravam água suja pelas janelas e mesmo os dejetos dos penicos. De modo que, para proteger os transeuntes, foi tornado obrigatório, em 1372, gritar 3 vezes "Cuidado com a água!", antes de atirar água pela janela. Regos de água choca mal cheirosa corriam pelo meio das ruas e quando chovia era praticamente impossível transitar nelas. 
Industrial (Manchester, Sheffield, Nottingham ou Bradford) tinha sido sustentado, durante séculos, no uso dos rios. E foram, precisamente, os rios que permitiram incubar a Revolução Industrial. Aqui, como na Cidade do México, a maior parte desses rios são hoje subterrâneos.

Inclusive nos países que não conheceram a experiência da Revolução Industrial, ou que a viveram mais tarde e de forma mais limitada que a Inglaterra, os rios não escaparam a essa função social de funcionarem como reservatórios dos despojos de uma sociedade cada vez mais concentrada em grandes cidades. O Brasil, a China e a Índia, que são economias emergentes com populações numerosas, são disso um exemplo. A Índia, por exemplo, é conhecida por ter um incomensurável problema de poluição das águas, devido ao lançamento dos esgotos não tratados nos rios. O Ganges, o Yamuna e o Kaveri, que atravessam zonas densamente povoadas, têm elevados níveis de poluição. Em 11 de dezembro de 2011, a revista "The Economist" (The Economist, 2011), num dossier especialmente consagrado à Índia, abordava especificamente essa questão da seguinte forma:

Para saber por que morrem todos os dias, de diarreia, 1000 crianças indianas, faça um pequeno passeio ao longo do Ganges em Varanasi. Quando entra na cidade, o rio sagrado do Hinduísno contém 60000 bactérias de coliformes fecais em cada $100 \mathrm{ml}$ de água, 120 vezes mais do que é considerado seguro para tomar um banho. Quatro milhas mais abaixo, com o insumo de 24 canos de esgoto jorrantes e com 60000 peregrinos a banharam-se no rio, a concentração é 3000 vezes acima do limite de segurança. Em alguns lugares, o Ganges torna-se preto e séptico. Cadáveres, de adultos semicremados ou de bebés cobertos com mortalhas, fluem pelo rio.

\section{Processos fluviais e processos de urbanização}

A urbanização e a industrialização, sobretudo na Europa e na América do Norte, são os dois processos mais marcantes da transformação dos rios, assim como da diversificação dos seus usos sociais (Castonguay e Evenden, 2012). A partir do século XVIII, sobretudo nas áreas urbanas e industriais, as margens dos rios começam a ser regularizadas, potenciando a navegabilidade e o comércio, ao mesmo tempo que se controlavam as cheias. Essas operações, que correspondem a um primeiro momento de intervenção estatal nos rios, caracterizam-se por reduzir as dimensões de sociabilidade da água e dos cursos de água. Gabriele Lechner defende que o Estado, sob o pretexto de estar a controlar as inundações, vai consumar $\mathrm{o}$ isolamento entre as cidades e os rios, ao mesmo tempo que isso the permite mais facilmente cobrar impostos sobre a circulação nos rios (Lechner, 2006). Para a autora, os séculos XIX e XX assistem à realização de projetos fluviais de cada vez maior envergadura, uns ligados à agricultura, outros à indústria e outros ao comércio. Ao mesmo tempo, nas cidades, os portos urbanos perdem relevância ou extinguem-se, "os últimos braços mortos dos rios desaparecem e os pequenos afluentes, inicialmente canalizados, são enterrados." (Lechner, 2006: 8) Os grandes projetos hídricos e hidroelétricos alteram os caudais, mudam os fluxos, as relações da população com os rios, o clima, as paisagens e a identidade local. 
A evolução da ciência moderna e, com ela, a invenção da hidrologia levaram a uma transformação sem precedentes dos rios. A abertura do canal do Midi, em 1681, para ligar o Atlântico ao Mediterrâneo foi apenas o primeiro passo de um processo que a ciência moderna viria ampliar e acelerar. Mauch e Zeller (2008) destacam o facto relevante de este processo de pacificação dos rios ter ocorrido, em muitos casos, debaixo da alçada de empreendimentos militares. Nos EUA, a instituição mais importante de gestão dos rios é ainda um braço militar, nomeadamente a Army Corp of Enginneers (Mauch e Zeller, 2008: 3). Melissa Samet que faz uma análise detalhada de vários grandes projetos de transformação dos rios americanos, conclui ser necessário desenvolver projetos sem a Army Corps (Samet, 2007) e Paul Kibel refere-se a esses projetos como "Cavalos de Tróia" que facilitaram fenómenos devastadores como os do furacão Katrina (Kibel, 2007: 200). Dessa transformação sem precedentes faz parte o boom mundial de construção de barragens, que se iniciou nos anos 1930, por vezes associado a fenómenos de transvase de uns rios para os outros. Mauch e Zeller (2008) dão conta que nos anos 1970 eram lançados, em média, mais de dois concursos públicos diários de construção de barragens e que a World Comission on Dams estima que cerca de 80 milhões de pessoas tenham sido deslocadas em virtude deste processo. Estes autores salientam ainda o facto de, em 2000, a World Comission on Dams ter registado a existência de mais de 45 mil grandes barragens em todo o globo. Relevando que a construção de barragens preenche importantes funções simbólicas, na medida em que glorifica a capacidade das nações, é sinónimo de desenvolvimento e progresso económico. Daí que tenha sido um fenómeno que não se limitou aos países mais desenvolvidos, tendo conhecido também um forte impulso nos países do hemisfério sul que se tinham libertado da colonização, sendo que a maior barragem à face da Terra (Hidroelétrica das Três Gargantas) foi concluída já no século XXI (em 2006, na China). Os rios, hoje como sempre, participam nos processos de construção identitária das nações, preenchendo um uso social de vincado teor político e ideológico. Não é despiciendo notar que os atuais maiores projetos de construção de barragens estejam a ocorrer nas nações emergentes que fazem parte dos BRIC, designadamente a China, a Índia, a Rúsia e o Brasil³.

Com estas mudanças, e sobretudo com a perda de importância do comércio de proximidade para o comércio global, mas também com a emergência, no século XX, de novos meios de transporte, os rios veem abrandar ou enfraquecer muitas das funções económicas que tinham tido no passado. Na segunda metade do século XX, e em alguns países ainda na primeira metade do século, a prioridade passa a ser dada ao transporte rodoviário e ferroviário. Como os vales dos rios, e em concreto as suas margens, se apresentavam como os locais mais adequados para desenvolver essas infraestruturas (até porque, em geral, o relevo era menos acidentado e porque, sendo terrenos públicos, não tinham custos de aquisição ou de expropriação), o que acabou por acontecer foi um agravamento da separação dos rios de todo o seu entorno. Antes consumado pelo desenvolvimento da indústria e das obras de regularização das margens. Depois, mesmo em meio urbano, pela construção de infraestruturas rodoviárias

3 A China tem a maior central hidroelétrica do mundo, sendo que o Brasil tem 3 das 10 maiores e a Rússia tem duas. 
e ferroviárias. Gabriele Lechner sustenta que os rios são relegados para segundo plano, para um lugar visível mas inacessível, e que a ligação entre margens se torna muitas vezes impossível (Lechner, 2006).

À medida que os rios iam perdendo as suas funções económicas tradicionais, depois de terem estado sujeitos às pressões do crescimento demográfico, aos usos que os tornaram lixeiras e canais de esgoto, aos malefícios ambientais da agricultura produtivista e às consequências da Revolução Industrial, uma outra ameaça decorrente do processo de urbanização estava por vir. A segunda metade do século XX e o crescimento urbano das metrópoles, designadamente nas regiões menos desenvolvidas do mundo, estão particularmente marcados por conflitos entre processos fluviais e processos de urbanização. Lucia Costa traduz este conflito na fórmula "cidades invadindo as águas e águas invadindo as cidades." (Costa, 2006: 10)

Se é verdade que durante séculos as cidades se debateram com o problema das cheias, não é menos verdade que o fenómeno inverso, as cidades invadindo os rios de todos os modos, se tornou mais recorrente e mais grave. E não se trata apenas de habitações informais ou irregulares em relação às quais os poderes públicos fecham os olhos. Em muitos casos, alguns deles dramáticos, correspondem a políticas estatais deliberadas. Na China, o desenvolvimento urbano aniquilou, desde os anos 1990, em cada ano, cerca de 1000 rios com bacias hidrográficas superiores a $60 \mathrm{Km}^{2}$. Dos cerca de 50 mil rios com bacias hidrográficas acima dos $62 \mathrm{Km}^{2}$, que existiam na China há 20 anos atrás, 28 mil despareceram. A certeza que os rios, direta ou indiretamente, vão dar ao mar é uma verdade cada vez mais questionável. Progressivamente, sobretudo nas grandes cidades, foi-se tornando cada vez mais difícil para os pequenos rios o atravessamento dos tecidos urbanos. Os conflitos entre os processos fluviais e os processos de urbanização, devido à especulação imobiliária, ao alargamento incessante das malhas urbanas e à permissividade construtiva em cima e na proximidade das linhas de água, tem conduzido a alterações drásticas na estrutura ambiental dos rios (Costa, 2006). Paradoxalmente, se uns rios desaparecem, outros, por via dos processos de sedimentação agravados por processos de construção de edifícios, diques e barragens, veem o seu leito subir de nível a um ritmo sem precedentes.

Por outro lado, atendendo a que os processos de urbanização mais intensos ocorrem atualmente nas zonas menos desenvolvidas do mundo, em muitos casos sob a forma de construção de favelas, e que grande parte da construção de favelas na Ásia está a ocorrer nas margens dos rios, Kate Harriden questiona-se sobre o impactos da "slum urbanisation" nos processos fluviais dos rios tropicais (Harriden, 2012). Na opinião da autora, para se fugir a uma visão demasiado ocidental e maniqueísta, é forçoso reconhecer que a relação entre processso fluviais e processos de urbanização não se fez num dia, nem por todo lado do mesmo modo e que os rios tropicais têm especificidades próprias que caracterizam essa relação.

\section{Esse rio é a minha rua}

Durante muito tempo, as cidades e as pessoas viraram as costas aos rios, limitando-os a usos industriais e comerciais e empobrecendo as funções sociais que eles podiam desempenhar, 
e empobrecendo igualmente as culturas que os rios fizeram emergir através das suas paisagens e dos seus usos sociais (Halgand, 2010). No séculos XIX e XX, as pessoas fugiam das cidades, procurando redutos circundantes na natureza, para poderem praticar lazeres fluviais. São muitas as cidades de hoje que lamentam o facto de estarem de costas voltadas para o rio que as atravessa. A partir da segunda metade do século $X X$, e muito particularmente nas últimas décadas do século, num segundo momento de intervenção estatal, e com as preocupações relativas aos distúrbios ambientais a agravarem-se, assim como a tomada de consciência em relação à finitude dos recursos naturais, sendo a água o mais importante, os rios voltam a entrar nas agendas urbanas promovendo formas de reconciliação com as cidades (Gorski, 2010). Em todo o caso, a ideia que estamos a passar de uma fase de rutura entre rios e cidades para uma fase de reconciliação (idem) ou a ideia que a requalificação das frentes de água e das margens dos rios permite ultrapassar as limitações das fases anteriores da requalificação urbana (Kibel, 2007) são argumentos que nos parecem um pouco forçados. São muitas as ameaças que pairam sobre os rios e, não obstante os bons exemplos, muito está por fazer. Convém lembrar que os autores europeus que escrevem sobre os rios tendem a focar-se mais nos aspetos ambientais e culturais e, ao contrário do que acontece com os autores americanos, menos nas políticas de água. Os europeus tendem igualmente a concentrar-se nas várias funções económicas, sociais e culturais dos rios urbanos (Mauch e Zeller, 2008). Nessa medida, na Europa, tem-se menos uma análise que incida sobre o rio na sua globalidade, pelo que é fundamental que não se tome o todo pela parte que nos está a permitir ver e viver hoje os rios de uma outra forma.

Ainda assim, é inegável que existem agendas internacionais e modelos globalizados de intervenção que estão a trazer os processos fluviais para o centro dos debates sobre as questões urbanas. Ao mesmo tempo que reivindicações relativas à qualidade de vida e à sustentabilidade urbana parecem querer dar ao rios o estatuto de rua que eles já tiveram. Também aqui, convém não esquecer, todavia, como lembra Maria Cecília Gorsky (Gorski, 2010), a "cantilena saudosista e nostálgica" que enfatiza o facto de os rios já terem sido significativos, de trazerem lembranças agradáveis da sua época de balneabilidade, de terem representado uma fonte de rendimento e de riqueza e de terem contribuído para a formação das paisagens. Até porque, a importância que os rios parecem estar a assumir se resume muitas vezes a intervenções simbólicas e localizadas que participam da ideologia da promoção da qualidade de vida. Tanto mais que essas intervenções parecem estar vocacionadas para que os rios preencham a função social de alimentar um mercado urbano de lazeres e a cultura visual do consumo.

Nesta perspetiva, é curial registar que os rios passaram ou estão a passar de uma dimensão funcional a uma dimensão patrimonial. Gabriele Lechner constata que a água, que foi progressivamente banida do meio urbano, está de volta às cidades (Lechner, 2006). Esta inversão de processos, particularmente visível nas áreas de antigos portos e de zonas industriais decadentes, está a fazer emergir projetos de requalificação e de construção de novas centralidades urbanas. Os rios votados ao esquecimento estão hoje a ser inseridos nas estratégias urbanas de desenvolvimento. "Tornar as margens acessíveis", "integrá-las na organização urbana", "virar a cidade para o rio", "colocar o rio no coração da cidade", são hoje fórmulas amplamente divulgadas pelos agentes desses processos que 
catapultam os rios para o seio das estratégias locais de desenvolvimento. Nas grandes e nas pequenas cidades, zonas de lazer e espaços de prática de desportos náuticos multiplicam-se para favorecer o turismo fluvial (Lechner, 2006).

É ainda Gabriele Lechner (2006) que constata o desejo transversal de, numa ótica patrimonial, se promover a integração das paisagens nos projetos de ordenamento urbano. Tanto mais que, atualmente, a água se apresenta globalmente como um bem raro e ameaçado, o que faz com que os rios adquiram essa função social de elemento estrutural da paisagem e do património. O termo paisagem não é apenas um termo incontornável e omnipresente dos projetos de requalificação das frentes de água. É sobretudo um elemento federador que permite dar conta da continuidade dos espaços fluviais, que fazem da cidade parte de um território mais vasto e que permitem tentar encontrar coerências territoriais a uma escala mais ampla (2006, p. 47). É neste contexto que se pode afirmar que os rios, depois de terem passado de paisagens fluviais a paisagens urbanas, estão hoje a passar para uma dimensão patrimonial.

Foz

Os rios são agentes da História (Stroshane, 1998). Os grupos humanos alteraram as características dos rios ao longo do tempo, adaptando-os a diferentes usos económicos e sociais. A revolução industrial e urbana que ocorreu no mundo ocidental foi o fenómeno que mais alterou o modo como as sociedades usam os rios. Com essa revolução, os rios "entraram no processo de urbanização. (...) A urbanização refez os rios, é certo, mas os rios também limitaram as possibilidades, moldando as formas e as funções urbanas, e com uma previsível imprevisibilidade desafiaram as fundações da vida urbana com riscos de vários tipos." (Castonguay e Evenden, 2012: 238) Nessa medida, "as necessidades sociais e económicas, os valores ecológicos, as preferências estéticas e as identidades nacionais moldaram as perceções e o design dos rios em diferentes regiões e países (Mauch e Zeller, 2008: 7). Por isso, é forçoso reconhecer que, além das tendências comuns, cada rio tem as suas especificidades e que os rios e os desafios que se lhes apresentam estão hoje longe de constituir uma realidade única com soluções modelares. Na dimensão patrimonial que hoje assumem através do conceito de 'paisagem fluvial' e das operações de requalificação em curso, os rios transportam um desafio maior. O de promover a apreensão global do território que eles atravessam, fomentando intervenções integradas de ordenamento e de animação ao longo do seu curso.

\section{Bibliografia}

Castonguay, Stéphane e Matthew, Dominic (Orgs.) (2012), Evenden. Urban Rivers: Remaking Rivers, Cities, and Space in Europe and North America. Pittsburgh: University of Pittsburgh Press.

Costa, lucia Maria Sá Antunes (2006), "Rios urbanos e o desenho da paisagem." Rios e palsagens urbanas em cidades brasileiras, lucia Maria Sá Antunes Costa (Org.). Rio de Janeiro: PROURB-FAu-UfrJ, 9-15. 
Gorski, Maria Cecílla Barbieri (2010), Rios e cidades: ruptura e reconcillação. Rio de Janeiro: SenaC. Guillerme, André (1983), Les temps de l'eau - La Cité, l'Eau et les techniques. Seyssel: Editions Champ Vallon. Halgand, Nathalie (2010), Le paysage fluvial urbain. Paris: Centre de ressources documentaires de L'Inp. Harriden, Kate (2012), Potential impacts of slum urbanisation on channel bank storage in the Bang Pakong River, Thailand. Water Practice \& TeChnology 7(4), 1-7.

Kelm, George L. (1991), "Rivers and Waterways in the Bible". Holman Bible Dictionary. Trent C. Butler (Org.). NASHVILLE: BRoAdMAN \& Holman.

Kibel, Paul Stanton (2007), Rivertown: Rethinking Urban Rivers. Cambridge, MA: Mit Press.

Lechner, Gabriele (2006), Le fleuve dans la Ville - la valorisation des berges en milieu urbain. Paris: Directio Générale de L'URBanisme de L'Habitat et da la CONSTRUCtion.

Mauch, Christof e Thomas Zeller (2008), Rivers in history: perspectives on waterways in Europe and North America. Pittsburgh: University of Pittsburgh Press.

McMillin, Tracy S. (2011), The Meaning of Rivers: Flow and Reflection in American Literature. Ames: University of IOWA PRESS.

Samet, Melissa (2007), "Bankside Federal." Rivertown - Rethinking Urban Rivers. Paul Stanton Kibel. Cambridge - MA: MIT PRESS, 143-177.

Schneider, Wolf (s. D.) De Babilônia a Brasilla: a cidade como destino do homem, de UR a Utopia. São Paulo: Boa Leitura. Stroshane, Tim (1998), The social lives of rivers. Capitalism, Nature, Socialism 9(3), 147-150.

The Economist (2013), "Creaking, groaning I The Economist." The Economist. 11 de dezembro de 2011. Consultado EM HTTP://WWW.ECONOMIST.COM/NODE/12749787, EM 9 DE MAIO DE 2013.

Varejka, Pascal (1998), Paris au Moyen âge: oyez, oyez, braves gens, la véridique histoire de la grande Cité au temps des cheValiers et des ménestrels. Paris: Parigramme.

Vettorello, Cécile e Marie Vignau (s. d.), L'eau et la santé à lyon - La formation d'une cité. Lyon: Agence d'Urbanisme DE LYON. 